\title{
Um conselho de políticas públicas e o cárcere: o Conselho estadual de Política Criminal e Penitenciária de São Paulo e o 'accountability' em direitos humanos de pessoas presas.
}

\author{
Dias de Souza Ferreira, Otávio \\ Um conselho de políticas públicas e o cárcere: o Conselho estadual de Política Criminal e Penitenciária de São \\ Paulo e o 'accountability' em direitos humanos de pessoas presas. \\ Administração Pública e Gestão Social, vol. 11, núm. 3, 2019 \\ Universidade Federal de Viçosa, Brasil \\ Disponível em: http://www.redalyc.org/articulo.oa?id=351559268005
}

Esta obra está bajo una Licencia Creative Commons Atribución-NoComercial-SinDerivar 3.0 Internacional 


\title{
Um conselho de políticas públicas e o cárcere: o Conselho estadual de Política Criminal e Penitenciária de São Paulo e o 'accountability' em direitos humanos de pessoas presas.
}

\author{
A public policy council and the jail: the São Paulo's Council on Criminal and Penitentiary Policy and the \\ accountability in prisoner's human rights. \\ Un consejo de políticas públicas y la cárcel: el Consejo estadual de Política Criminal e Penitenciária de Sao Paulo y el \\ 'accountability' en derechos humanos de personas reclusas.
}

Otávio Dias de Souza Ferreira

Universidade de São Paulo, Brasil

Redalyc: http://www.redalyc.org/articulo.oa?

euotavio@gmail.com $\mathrm{id}=351559268005$

Recepção: 20 Fevereiro 2017

Aprovação: 20 Julho 2018

Publicado: 01 Julho 2019

\section{Resumo:}

O Conselho de Política Criminal e Penitenciária de São Paulo é um colegiado pertencente ao organograma da Secretaria de Administração Penitenciária, fundado em 1987, de composição plural e mista. Vislumbrando algum potencial do Conselho no sentido de contribuir no accountability em direitos humanos no sistema prisional, a pesquisa investiga limites e virtudes do colegiado, considerando aspectos institucionais e seu funcionamento na prática. Analisou-se documentos legais e institucionais e foram realizadas entrevistas semi estruturadas com conselheiros de diferentes gestões do colegiado e com pessoas envolvidas com o sistema prisional de São Paulo. Os resultados da pesquisa apontam para um colegiado fraco, com limitações concernentes ao desenho institucional e à falta de autonomia em relação à instituição sobre a qual deveria exercer controles democráticos. Quanto às suas virtudes, ressalta-se o potencial do arranjo institucional em ativar fluxos de informações e de demandas sobre assuntos criminais e prisionais, com o condão de influenciar as atividades dos múltiplos atores com capacidade do exercício de controles democráticos nesse campo.

Palavras-chave: Direitos Humanos, Participação Política, Controles da Administração Pública, Prisões, Conselho Penitenciário.

\section{Abstract:}

The São Paulo's Council on Criminal and Penitentiary Policy is a collegiate on the organizational chart of the Secretariat of Penitentiary Administration, founded in 1987, with a plural and mixed composition. Assuming that the Organ has some potential to contribute to human rights accountability in the prison system, this research investigates the limits and virtues of the Council, considering both its institutional framework and actual functioning. Legal and institutional documents were analyzed. We also carried semi-structured interviews with counselors experienced in different periods of the collegiate history, as well as with people involved in the São Paulo's prison system. The findings point to a weak collegiate, with limitations in its institutional design and lack of autonomy with regard to the very institution it should exercise democratic controls. As for its virtues, we emphasize the potential of the institutional arrangement to activate flows of information and demands on criminal and prison issues, aiming to influence the activities of the multiple actors with accountability capacities in this field.Keywords: Human Rights, Political Participation, Control of Public Administration, Prisons, Prison Council.

\section{Resumen:}

El Consejo de Política Criminal y Penitenciaria de São Paulo es un arreglo institucional perteneciente al organigrama de la Secretaría de Administración Penitenciaria, fundado en 1987, de composición plural y mixta. Vislumbrando algún potencial del Consejo para contribuir en la responsabilidad social en derechos humanos en el sistema penitenciario, la investigación busca límites y virtudes del Consejo, considerando aspectos institucionales y su funcionamiento en la práctica. Se analizaron documentos legales e institucionales y se realizaron entrevistas semiestructuradas con consejeros en diferentes gestiones del colegiado y con personas involucradas en el sistema penitenciario de São Paulo. Los resultados apuntan a un colegiado débil, con limitaciones concernientes al diseño institucional ya la falta de autonomía en relación a la institución sobre la cual debería ejercer controles democráticos. Cuanto a sus virtudes, se resalta el potencial del arreglo institucional en activar flujos de informaciones y de demandas sobre asuntos 
criminales y prisioneros, capaces de influenciar las actividades de los múltiples actores con capacidades de responsabilidad social en este campo.

Palabras clave: Derechos Humanos, Participación Política, Control de la Administración Pública, Cárceles, Consejo Carcelário.

\section{INTRODUÇÃo}

Ainda que coexistam órgãos e instituições com potencial de controles democráticos orbitando em torno do sistema prisional do Estado São Paulo, como o Ministério Público, as Corregedorias Judicial e Administrativa, uma ouvidoria, a Defensoria Pública e uma Comissão Parlamentar Permanente na Assembleia Legislativa, constituindo uma espécie de rede, as denúncias de violações de direitos humanos nos cárceres seguem infindáveis.

As degradantes e violentas condições de vida nas prisões paulistas agravaram-se com a ampliação de sua população sem a correspondente expansão do número de vagas. Aproveitando-se desse cenário, o surgimento e a consolidação do Primeiro Comando da Capital, o PCC, como poderoso ator político no sistema prisional impactou os esforços de controles democráticos em matéria de direitos humanos no sistema prisional (Goes, 2009. Dias, 2013. Ferreira, 2014). Se o sistema prisional costuma ser muito oculto em termos de rendição de contas, a impopularidade desse ator e o incômodo da sua presença em nada ajudaram no combate ao fechamento dos estabelecimentos para os atores externos, na reversão de tendências mais punitivistas de autoridades e no exercício dos controles democráticos dos diversos atores da rede de accountability. Pautas e tentativas de reformas vêm sendo bloqueadas e os esforços na defesa dos direitos humanos de acusados e condenados por infrações penais, sem nunca ter gozado de simpatia popular, têm sofrido contínuos ataques de lobbies conservadores nas últimas décadas (Adorno, 1999). Nesse cenário de conflitos é que se deu o funcionamento do Conselho Estadual de Política Criminal e Penitenciária (CEPCP) ao longo desses últimos anos.

combate

Este artigo busca compreender os limites e as virtudes do CEPCP/SP com base na premissa de que o arranjo institucional de composição mista e plural apresenta um potencial como espaço para a accountability em relação a violações de direitos humanos de pessoas presas.

Para evitar ruídos de compreensão, importa desde já definir mais precisamente alguns conceitos. Os tais "direitos humanos de pessoas presas" estão previstos em normas internacionais e nacionais ${ }^{[2]}$, compreendendo diversas categorias, como os direitos à saúde, à educação, à assistência jurídica, material e religiosa e à integridade física e moral. A noção de accountability adotada envolve de modo mais amplo os controles democráticos, a transparência e prestação de contas, na lógica de uma rede de controles institucionais internos e externos ao Estado. Considera-se a "sociedade civil" não de modo puro e nem idealizado, mas como agência com alguma separação do Estado e do mercado, com transversalidades complexas em interaçóes entre indivíduos e atores coletivos, comportando uma multiplicidade de clivagens e de estatutos políticos (Gurza Lavalle, Houtzager \& Castello, 2012).

Trata-se de um estudo eminentemente empírico com base em uma abordagem qualitativa, que dialoga, sobretudo, com um aporte teórico da Ciência Política e que parte da premissa normativa de que o aperfeiçoamento da accountability em direitos humanos no sistema prisional é algo positivo e capaz de impactar na garantia de um sistema de penas mais justo, com menos arbítrio e violência e gerador de custos sociais menos danosos para a sociedade.

$\mathrm{Na}$ realização do trabalho este pesquisador deparou-se com algumas complicações, como a carência de registros históricos sobre as atividades do órgão e a inatividade do colegiado durante o período de pesquisa empírica ${ }^{[3]}$. Entre as estratégias para viabilizar o trabalho, foram consultadas fontes documentais esparsas, 
como publicações nos Diários Oficiais, reportagens, artigos de opinião e relatórios de pesquisa, formularamse pedidos de acesso à informação com base na Lei Federal $n^{\circ}$ 12.527, de 12 de novembro de 2011, perante a Secretaria de Administração Penitenciária ${ }^{[4]}$ e foram realizadas entrevistas semiestruturadas com representantes de órgãos e instituições do Estado, de organizações de defesa dos direitos humanos, com egressos do sistema prisional e seus familiares ${ }^{[5]}$. Embora tenham sido raras as informações encontradas referentes ao funcionamento do colegiado no momento mais próximo de sua fundação, a amplitude dos conteúdos encontrados permite iluminar respostas para as questões almejadas na pesquisa, referentes às virtudes e aos limites do CEPCP na questão dos controles democráticos em direitos humanos de pessoas presas.

Este artigo está organizado em três seções, além dessa parte introdutória e de seu fechamento sintético, no que vem a ser a parte das considerações finais. O próximo item traz o desenho institucional e informações diversas da estrutura do colegiado. O item seguinte apresenta uma análise sobre a composição do Conselho, a sua relação com a instituição sobre a qual pode exercer accountability e sobre o seu potencial de exercício de controles democráticos na questão dos direitos humanos de pessoas presas, considerando especialmente aspectos da teoria democrática contemporânea e também sobre a representação e a deliberação. Na sequência são reunidos alguns depoimentos colhidos durante a pesquisa, expondo algumas impressões em uma abordagem qualitativa a respeito da atuação do Conselho.

O CEPCP, fundado em 1987, em um contexto histórico de multiplicação de experiências participativas orientadas pelas noções de controles sociais democráticos na América Latina (Gurza Lavalle \& Isunza, 2011), ao reunir membros de várias dessas instituições em um colegiado, tem um potencial de proporcionar alguma abertura democrática no aparato estatal do sistema prisional e de afetar o funcionamento de rede de accountability com potencial para atuar no combate a violações de direitos humanos no sistema prisional. Trata-se de um colegiado vinculado ao organograma institucional da Secretaria de Administração Penitenciária estadual, dotado de uma composição plural e mista, que pode ser considerado um "conselho de políticas públicas" pelas suas atribuições institucionais consultivas em temáticas de política criminal e penitenciária, e por ter sido fundado em um contexto de criação de órgãos plurais e mistos para a promoção de uma abertura do aparato estatal, mesmo que não tenha a força institucional daqueles "conselhos gestores de políticas públicas” consagrados na Constituição Federal de $1988^{[1]}$.

\section{Notas SOBRE O DESENHO E A ESTRUTURA do COLEgiAdo}

O início da década de 1980 em São Paulo constituiu um momento virtuoso de debates políticos sobre a questão carcerária, envolvendo membros de diversos setores da sociedade, incluindo políticos, intelectuais, juízes, dirigentes do sistema prisional e militantes. No Governo Franco Montoro levou-se para a agenda política uma preocupação para com as denúncias de violações de direitos de presos comuns e foram empreendidas políticas públicas inovadoras no cárcere, como a implantação de urnas no interior de estabelecimentos prisionais, destinadas a colher denúncias e queixas por parte dos próprios presos, e a eleição de representantes dos internos, para atuarem na mediação de demandas perante as autoridades do Executivo e do Judiciário ${ }^{[6]}$.

Na esfera da União, entre 1975 e 1976, alguns Congressistas emplacaram uma Comissão Parlamentar de Inquérito (CPI) em Brasília sobre a questão carcerária no Brasil e, nos anos que se seguiram, especialistas se reuniram para formular a Lei de Execução Penal (Brasil, 1984b), bem como para promover a reforma da Parte Geral do Código Penal (Brasil, 1984a), ambas concluídas em 1984 (Teixeira, 2009), consagrando múltiplos direitos para as populações encarceradas.

Em 1980 foi fundado o Conselho Nacional de Política Penitenciária (CNPP), por meio da Portaria ${ }^{\circ}$ 658, de autoria do então Ministro da Justiça Ibrahim Abi-Ackel, com a genérica finalidade de "elaborar 
diretrizes, estabelecer normas e coordenar a execução da política penitenciária no território nacional” (Brasil, 1980b). O seu funcionamento foi regulado em novembro daquele ano, prevendo uma composição original de 11 membros (Brasil, 1980a). Com a edição da Lei de Execução Penal em 1984 (Brasil, 1984b), esse órgão passou a se chamar Conselho Nacional de Política Criminal e Penitenciária (CNPCP). O artigo ${ }^{\circ}$ 64 dessa lei fixou as seguintes incumbências legais para o CNPCP: a proposição de diretrizes da política criminal, a sugestão de prioridades da política criminal e penitenciária, a promoção de avaliação periódica do sistema criminal, o estímulo à pesquisa criminológica, a elaboração do programa nacional penitenciário de formação e aperfeiçoamento do servidor, o estabelecimento de regras sobre a arquitetura e construção de estabelecimentos, a determinação de critérios para a elaboração da estatística criminal e a inspeção e fiscalização de unidades prisionais, podendo requerer sindicâncias e representar perante a autoridade competente a interdição das unidades. Em 1987, uma resolução do CNPCP recomendou a todos os estados da federação a criação de Conselhos Estaduais de Política Criminal e Penitenciária junto às suas Secretarias de Justiça ou de órgãos que tivessem funções correspondentes (Brasil, 1987).

Seguindo essa recomendação, a norma criadora do CEPCP em São Paulo foi editada em 1987 pelo então Governador Orestes Quércia (São Paulo, 1987a). Assim, o colegiado foi concebido com base e nos moldes do CNPCP, de 1984, que, por sua vez, havia se baseado no CNPP, de 1980.

O nome do Conselho remete a duas espécies diferentes de políticas, as criminais e as penitenciárias. Quanto às políticas penitenciárias, há menos problemas de definição, pois o próprio nome já traz uma delimitação do assunto referente às questões que envolvem o universo prisional. Quanto às políticas criminais, Zaffaroni et al (2003: 273) preconizam que elas costumam servir como um "discurso legitimante do poder punitivo", quando deveriam ser a resultante da interdisciplinaridade entre o Direito Penal e a área da Ciência Política voltada para a engenharia institucional. A Ciência Política nesse contexto desempenharia a função de fornecer informações sobre as consequências e "o sentido político geral do quadro de poder em que toma suas decisões" - os legisladores e os julgadores - que pode ser "liberal ou autoritário, garantidor ou policial, isto é, reforçador ou debilitador do estado de direito".

O artigo $4^{\circ}$ do Decreto de instituição do CEPCP (São Paulo, 1987a) previu as seguintes funções:

- I. Cumprir e fazer cumprir as diretrizes do Conselho Nacional de Política Criminal e Penitenciária; II. assessorar o Secretário de Justiça na execução da política criminal e penitenciária do Estado e na harmonização das atividades dos vários órgãos nela envolvidos;

III. propor as diretrizes da política estadual quanto à prevenção do delito, administração da justiça criminal e execução das penas e das medidas de segurança;

IV. contribuir na elaboração dos planos estaduais de desenvolvimento, sugerindo as metas e prioridades da política criminal e penitenciária;

V. promover a avaliação periódica dos sistemas criminal e penitenciário para a sua adequação às necessidades do Estado;

VI. estimular e apoiar a pesquisa criminológica;

VII. sugerir regras sobre a arquitetura e a construção de estabelecimentos penais e casas de albergados;

VIII. promover inspeções nos Estabelecimentos Penais, informar-se, mediante relatórios do Conselho Penitenciário, requisições, visitas ou outros meios, sobre o desenvolvimento de execução penal, propondo às autoridades dela incumbidas: as medidas necessárias ao aprimoramento da execução penal;a instauração de sindicância ou procedimento administrativo, em caso de violação das normas relativas à execução penal; a interdição, no todo ou em parte, de estabelecimento penal;

IX. colaborar com o Conselho Nacional de Política Criminal e Penitenciária, mantendo-o informado de suas atividades;

$\mathrm{X}$. propor à autoridade competente a celebração de convênios para a consecução de seus objetivos (São Paulo, 1987a). 
O artigo seguinte desse Decreto dispunha que o Conselho contaria com o apoio técnico e administrativo da Secretaria da Justiça, então incumbida da gestão dos assuntos penitenciários.

Em 10 de dezembro de 1991 a edição de uma Lei Estadual (São Paulo, 1991) deu um novo formato ao Conselho e previu, além das dez incumbências referidas, uma nova e importante atribuição: "XI - zelar pelo respeito aos direitos e garantias individuais do preso".

Essa lei foi concebida em um curto período da história de São Paulo em que a administração do sistema penitenciário ficou sob a alçada da Secretaria de Segurança Pública, entre março de 1991 e novembro de 1992. Antes desse período, ficava sob a responsabilidade da Secretaria de Justiça e, depois, da Secretaria de Administração Penitenciária. Percebe-se que a atribuição de "zelar pelo respeito aos direitos e garantias individuais do preso" não era algo previsto no Decreto de 1987.

A Secretaria de Estado dos Negócios da Justiça, na época chefiada por Mário Sérgio Duarte Garcia, editou, em 19 de agosto de 1987, o regimento interno do CEPCP, na Resolução no 37. Embora tenha sido editada uma nova lei para regular as atividades do Conselho, alterando várias disposições de seu desenho original, incluindo a atribuição de "zelar pelo respeito aos direitos e garantias individuais do preso". Até hoje esse regimento não foi revisto e continua em vigência.

A referida Lei Estadual de 1991 previu a seguinte composição para o CEPCP ${ }^{[7]}$ :

I - 1 (um) membro, que será o Presidente, indicado pelo Secretário da Segurança Pública;

II - o Coordenador da Coordenadoria dos Estabelecimentos Penitenciários do Estado;

III - 1 (um) representante do Conselho Penitenciário do Estado;

IV - 1 (um) representante da Fundação Estadual de Amparo ao Trabalhador Preso;

V - 1 (um) representante da Secretaria da Justiça e da Defesa da Cidadania;

VI - 1 (um) representante do Ministério Público;

VII - 1 (um) representante da Assistência Judiciária da Procuradoria Geral do Estado;

VIII - 1 (um) representante da OAB - Seção de São Paulo;

IX - 2 (dois) professores universitários das áreas de Direito Penal, Direito Processual Penal, Penitenciário e Ciências correlatas, indicados pelo Secretário da Justiça;

$\mathrm{X}-4$ (quatro) membros representativos da comunidade, indicados por entidades reconhecidamente dedicadas à proteção dos direitos humanos e aos estudos na área criminal e penitenciária.

Parágrafo único - Para os fins do disposto no inciso II do artigo 97 da Constituição do Estado de São Paulo, o Procurador Geral de Justiça, ouvido o Conselho Superior,

Em processos consultados por este pesquisador sobre o histórico do Conselho arquivados na Secretaria de Administração Penitenciária pode-se identificar todas as nomeações para o mesmo. Embora nas primeiras gestões os conselheiros tenham permanecido durante todo o mandato, a partir de 2004 houve um número considerável de substituições e nomeações de novos conselheiros durante a gestão ${ }^{[8]}$. Desde 1987 até os dias de realização da pesquisa não se constatou um apreço ao devido cumprimento dos prazos de fim de mandato, havendo quase sempre algum atraso até a designação dos conselheiros para a gestão seguinte ${ }^{[9]}$. Assim, o CEPCP tem sofrido com longos períodos de inatividade desde sua criação. Desde 1994 até 2013, um período de praticamente vinte anos, no qual seriam esperadas cerca de dez gestões, foram designadas apenas seis. $\mathrm{O}$ colegiado ficou desativado em vários anos, no período entre o final de cada gestão até a designação da composição da próxima.

Isso ocorreu desde o primeiro desenho institucional do CEPCP, quando as gestões eram anuais. Essa irregularidade na realização de atos de designação da composição do conselho se agravou com o novo desenho do Conselho, pós 1991. A mera apuração das datas da publicação no Diário Oficial do Estado dos atos de designação para as seis gestões, convocando os conselheiros para mandatos de um biênio, evidencia longos períodos de desativação do Conselho. 
A norma legal foi desobedecida por vezes na forma de recrutamento de alguns dos membros do colegiado, como professores universitários e representantes da comunidade ${ }^{[10]}$.

Merece nota, ainda, o caso de um conselheiro que atuou por três gestóes consecutivas no Conselho (1994-1996, 1998-2000 e 2001-2003), apesar de a Lei Estadual no 7.634/1991 (São Paulo, 1991) e o regimento interno do CEPCP permitirem apenas uma recondução.

Percebeu-se, também, uma baixa periodicidade de reuniões do colegiado. As ordinárias deveriam ser realizadas mensalmente, mas, conforme os depoimentos de vários conselheiros das últimas gestões, ocorriam apenas em alguns poucos meses do ano. Algumas vezes havia falta de quórum mínimo, mas em outras, simplesmente as reuniões não eram convocadas. Por um ou outro motivo, por exemplo, entre agosto de 2012 e fevereiro de 2013, nenhuma reunião do CEPCP ocorreu.

Quanto à estrutura organizacional, o Conselho não dispõe de uma sala permanente e a sede física para a realização das reuniões varia conforme a gestão. Nas gestões em que a presidenta do CEPCP era a Presidenta da Fundação Prof. Dr. Manoel Pedro Pimentel (2008-2010 e 2011-2013), por exemplo, as reuniões eram marcadas para a sede daquela Fundação. $\mathrm{O}$ agendamento dos encontros era feito de forma unilateral pela presidenta e os convites eram enviados pela sua secretária pessoal para cada conselheiro, sem nenhuma publicação de edital ou divulgação em meios de comunicação. Não havia prática de elaboração de atas.

Algumas das rotinas pareceram afetadas por limitações relacionadas à imprecisão legal de dispositivos reguladores do conselho. Já houve confusão, por exemplo, quanto ao fato de o presidente ser ou não um membro adicional do colegiado, o que pode alterar o equilíbrio de forças políticas dentro do colegiado.

No primeiro formato do Conselho, em vigor entre 1987 e 1991, a Secretaria de Estado dos Negócios da Justiça, na época chefiada por Mário Sérgio Duarte Garcia, editou em 19 de agosto de 1987 um regimento interno do CEPCP (São Paulo, 1987b). Apesar das muitas inovações no desenho do CEPCP em 1991, o colegiado nunca logrou atualizar seu regimento interno, apesar da exigência legal expressa de conclusão dessa tarefa nos primeiros sessenta dias posteriores à instalação do colegiado ${ }^{[11]}$.

Como se verificou acima, no tocante ao desenho institucional e a aspectos de seu funcionamento na prática, o colegiado estudado padece de sérios problemas de estrutura, de descontinuidade do seu funcionamento ao longo dos anos e de desobediência aos próprios preceitos de sua regulação.

\section{UM DESENHO FAVORÁVEL AO ACCOUNTABILITY EM DIREITOS HUMANOS?}

A concepção do CEPCP/SP foi um dos atos iniciais da gestão do governador Orestes Quércia. Soube-se que a gestão de José Carlos Dias na Secretaria de Justiça do estado (1983-1986) - durante o Governo de Franco Montoro (1983-1987) - não teve qualquer influência na criação desse órgão (Dias, 2014). Uma hipótese considerada plausível pelo referido ex-Secretário de Estado em depoimento prestado a este pesquisador foi a de que a criação do CEPCP teria sido uma forma de acomodação de interesses em um momento político turbulento, contemplando diversos setores, como advogados, representantes de organizações da sociedade civil, membros de instituições públicas, logo após o rompimento de uma política ousada do Governo anterior focada em uma agenda política de direitos humanos para acusados e condenados por infrações penais, que incluía medidas de abertura e de controles democráticos do sistema prisional para a sociedade, além do atendimento a demandas dos internos referentes à melhoria das condições de reclusão. Essa política foi apoiada por setores da sociedade civil ligados à defesa de direitos humanos, mas enfrentou uma oposição ferrenha de setores sociais mais conservadores, em campanhas veiculadas pelos meios de comunicação (Goes, 2009; Dias, 2013; Ferreira, 2014). A garantia de assentos nesse novo conselho a atores de diversas instituições pode ter acalmado alguns ânimos descontentes de representantes de algumas instituições, mesmo que o novo órgão nascesse com limitada estrutura e sem garantias de autonomia.

Considerando que o colegiado tem competências consultivas, composição plural e alguma paridade entre membros do Governo e de outras instâncias do Estado e da sociedade civil organizada, parece evidente a 
existência de algum potencial para contribuir com a rede de controles democráticos em relação a direitos humanos de pessoas presas.

Esse novo arranjo participativo apresenta potencialidades no sentido de abertura democrática do aparato estatal, no sentido de fomentar:

[...] um importante aprendizado de convivência democrática, tanto para os atores da sociedade quanto do Estado. Tem exigido que o Estado dê publicidade a suas ações, apresente contas, exponha os critérios que balizam acordos; e, da sociedade civil, tem exigido que se qualifique para essa participação, o que amplia seu conhecimento dos processos que envolvem a gestão pública e possibilita a construção de novos referenciais capazes de equilibrar a defesa dos interesses privados e corporativos com o reconhecimento do caráter coletivo dos direitos implicados (Almeida \& Tatagiba, 2012: 73).

A criação do colegiado insere-se no contexto da redemocratização brasileira, quando novos arranjos institucionais de controles democráticos foram desenhados nas mais diversas áreas do Estado para desempenhar o papel de "controles democráticos não eleitorais institucionais mistos" (Vera \& Gurza Lavalle $2014)^{[12]}$. Pode se enquadrar na definição de "conselhos de políticas públicas” ${ }^{[13]}$, enquanto:

[...] espaços de articulação entre Estado e sociedade, nos quais as decisões sobre políticas públicas podem envolver um processo de discussão e busca de acordos públicos a partir da inclusão de diferentes segmentos da sociedade diretamente envolvidos com as políticas em questão (Cunha et al, 2011: 304).

Com atribuições consultivas em relação a decisões sobre políticas públicas, sem mecanismos de sanção e com ausência de dotação orçamentária própria, não se pode afirmar que houve efetiva "partilha de poder" [14] em relação ao CEPCP (Dagnino, 2002).

Pelo histórico relatado, a concepção do colegiado figurou como uma iniciativa de política pública conduzida muito mais no sentido "de cima para baixo" do que "de baixo para cima", para usar expressões contidas em um debate desenvolvido nas últimas décadas na literatura de avaliação e implementação de políticas públicas ${ }^{[15]}$. Nesse debate as políticas públicas costumam ser situadas entre os paradigmas "bottomup" (de baixo para cima) e "top-down" (de cima para baixo), conforme a sua formulação tenha sido fruto de uma construção envolvendo demandas de uma pluralidade de atores - podendo abranger a sociedade civil organizada, usuários de serviços públicos e agentes estatais das burocracias mais baixas ou do "nível de rua" ${ }^{[16]}$ - ou de uma decisão mais unilateral pelas elites políticas, respectivamente. Essa abordagem pode iluminar alguns pontos na análise do potencial do CEPCP para a accountability em direitos humanos no sistema prisional.

Parte da literatura participacionista mais recente tem valorizado um princípio de inclusão que priorize a participação daqueles indivíduos afetados diretamente pelas decisões dos colegiados ${ }^{[17]}$. No caso do sistema prisional, pode-se pensar na hipótese de inclusão de representantes das pessoas presas e seus familiares, aqueles que podem ser considerados como os "usuários" dos serviços prestados pela administração penitenciária, grupos hoje completamente excluídos das arenas políticas oficiais. Entre os benefícios da inclusão dessas pessoas pode-se vislumbrar um aprendizado mútuo de todos os atores, mediante a inclusão do local knowledge (Pateman, 1992; Fung, Wright, 2003), agregando ao sistema de políticas públicas demandas, aflições e opiniões daqueles públicos que têm contato direto com os problemas práticos da prestação dos serviços públicos, permitindo um novo fluxo de informações no sentido botton-up. Por uma argumentação semelhante, representantes da burocracia mais baixa do governo, como de agentes penitenciários, da streetlevel bureaucracy (Lipsky, 2010), também poderiam ter representação no colegiado.

Outras vertentes da teoria participacionista preconizam inovações democráticas com a participação de cidadãos ordinários leigos, como forma de evitar as disputas entre posições mais polarizadas do debate e com maior permeabilidade para refletir de forma racional em relação às informações dos experts (Gooding, Dryzek, 2008). Desse modo, a eventual carência de alguns conhecimentos técnicos específicos por parte de 
algum conselheiro leigo sempre poderia ser remediada a partir da consulta a um corpo técnico, a exemplo das assessorias dos Legislativos.

Contribuições da teoria deliberacionista sugerem que os membros dos conselhos que detiverem qualquer conhecimento técnico específico devem preocupar-se em justificar seus pontos de vista de modo racional, esclarecendo aos demais, na medida do necessário e com cuidados linguísticos, as regras válidas de lógica e metodologia que fundamentam o saber de seu conhecimento. Assim, o rigor científico deve contribuir exatamente para fortalecer a "clareza" do debate e ampliar a convicção do colegiado acerca de uma determinada deliberação (Christiano, 2007) ${ }^{[18]}$. Nesse sentido, Smith (2009) ressalta a importância de um julgamento ponderado (considered judgment) por parte de um colegiado de inovações democráticas.

Qualquer reflexão sobre o recrutamento de membros para colegiados como esses devem considerar a natureza impopular ${ }^{[19]}$ dos direitos humanos de pessoas presas ${ }^{[20]}$. Em temática de natureza contramajoritária, é preciso garantir uma sobre-representação de determinados grupos para prevenir o risco de que a tirania da maioria se reproduza ante a missão institucional do órgão ${ }^{[21]}$. Não parece que essa questão tenha sido objeto de preocupação quando da regulação do Conselho.

A representação não governamental em conselhos de políticas públicas, sobretudo quando se trata de assuntos de ordem contramajoritária, tais como a temática de direitos de pessoas presas, é dotada de uma complexidade maior do que a governamental,

[...] porque se, por um lado, os conselhos devem responder às exigências de pluralidade, por outro, isso pode significar a defesa de grupos antidemocráticos, que fazem de sua participação nos conselhos condição para a manutenção de privilégios e velhas práticas de negociação com o Estado. Como estabelecer critérios para a definição das entidades que podem ter assento nos conselhos, sem ferir o princípio democrático elementar que é o direito à participação nas decisões políticas? Além disso, à medida que se excluem grupos importantes e representativos da sociedade civil da representação nos conselhos, obstaculizase o processo de influência democratizante que esses espaços poderiam, potencialmente, exercer sobre essas organizações (Tatagiba, 2002:61).

Eventuais carências de legitimidade e de representatividade dos membros poderiam ser atenuadas pela comunicação do Conselho e dos conselheiros em relação a suas bases. A organização de audiências públicas convocando múltiplos atores para discutirem determinada temática é uma alternativa no sentido de reforçar os contatos institucionais e a própria imagem do conselho. Além de alimentar o fluxo de informações, de tornar o CEPCP mais conhecido, de agregar novas pautas, pode proporcionar maior força política a determinadas decisões do Conselho.

Entretanto, o CEPCP não tem se preocupado ao longo de sua história com iniciativas de prestação de contas, deixando de apresentar relatórios de sua atuação. Uma busca na rede mundial de computadores pelo nome do Conselho resultou basicamente em informações sobre a sua lei criadora e vai apontar como principal resultado a página eletrônica da Secretaria de Administração Penitenciária, na qual tudo o que aparece sobre o conselho são informações constantes na Lei Estadual n. 7.634/1991 (São Paulo, 1991), sobre suas atribuições e composição legal, além de referências sobre o ordenamento que rege esse órgão. Não aparece nenhuma informação sobre a última gestão e muito menos sobre o histórico do Conselho. Nem sequer um e-mail para contato é mostrado (São Paulo, 2013). Sem a transparência e a prestação pública de contas, a existência do colegiado tem permanecido pouco ou nada conhecida da população e da própria militância na temática de direitos humanos.

Para além das limitações institucionais referidas, o desprestígio do colegiado tem relações com a referida ausência de real "partilha de poder", com carências no tocante à publicidade e prestação de contas das ações do Órgão e com a política de inclusão de determinados atores em detrimento de outros no desenho do colegiado, afetando o fluxo de informações e as prioridades da agenda política do CEPCP. 


\section{IMPRESSÕES DOS CONSELHEIROS E DE ATORES ENVOLVIDOS COM O SISTEMA PRISIONAL}

Várias entrevistas realizadas ao longo da pesquisa permitem concluir que o CEPCP é muito pouco conhecido pelas pessoas ligadas de algum modo ao sistema prisional, seja pela pesquisa acadêmica, através de instituições do sistema punitivo, passando por organizações da sociedade civil, ou seja, parentes de internos ou egressos de estabelecimentos privativos de liberdade ${ }^{[22]}$. Entre aqueles que conheciam o órgão, diferentes percepções sobre o colegiado foram notadas mas, de modo geral, elas consagram mais elementos negativos do que positivos.

O antropólogo e cineasta Kiko Goifman, conselheiro na gestão 2001-2003, lembrou-se do início dos anos 2000 como um momento em que a sociedade civil ainda parecia entusiasmada e esperançosa com a nomeação de Nagashi Furukawa na Secretaria de Administração Penitenciária do estado de São Paulo (SAP/SP). O novo titular da pasta tinha reputação boa pelo êxito em sua experiência prévia em Bragança Paulista (SP). Nesse ambiente, as reuniões do CEPCP realizadas uma vez por mês, de manhã, em um espaço cedido pela Secretaria de Justiça e da Defesa da Cidadania, no Centro da cidade de São Paulo, costumavam ser cordiais, sem grandes conflitos. Kiko lembra-se de certa informalidade no ambiente, no qual algumas pessoas de fora do conselho, sobretudo membros de organizações de defesa de direitos humanos, participavam dos encontros ${ }^{[23]}$. Os assuntos principais discutidos no CEPCP de então constituíam-se em pautas caras ao Secretário de Estado, como a desativação do complexo do Carandiru, o esvaziamento das carceragens de delegacias e a criação de centros de detenção provisória com vistas a garantir espaço com mais dignidade para os presos provisórios. Eram temáticas que não produziam maiores atritos entre os conselheiros (Goifman, 2013). O psiquiatra Paulo César Sampaio foi conselheiro na gestão 2008-2010 quando, segundo ele, nada de muito relevante era discutido. Não parecia haver divisões, nem disputas internas, tampouco alguma tentativa de convencimento dos pares. As poucas reuniões ocorridas durante a gestão resumiam-se a conversas amistosas de uma hora de duração em uma sala de reuniões do edifício sede da Fundação Dr. Manoel Pedro Pimentel (Funap). Recorda-se que um dos temas mais recorrentes era a alteração do estatuto do Conselho. A Presidenta Lúcia Maria Casali de Oliveira - ex-promotora de justiça, então diretora-executiva da Funap - seria uma amiga pessoal do Secretário da SAP/SP e costumava definir unilateralmente as pautas (Sampaio, 2013).

A advogada Arlete da Silva Antonio, conselheira nessa mesma gestão, também indicada como representante da comunidade, endossou as palavras do depoente anterior. Apesar de lembrar-se de conflitos pontuais opondo a presidenta a outros conselheiros, como o membro do Ministério Público e a Defensoria Pública, a advogada considerava que a presidenta monopolizava os assuntos discutidos, insistindo demasiadamente em temas determinados, como a readequação do estatuto. Reclamou da falta de abertura do espaço para o questionamento das políticas do governo e do fato de as unidades prisionais escolhidas para as visitas do Conselho não serem as mais problemáticas ${ }^{[24]}$ (Antonio, 2013).

Na visão da Presidenta da Amparar, organização de mães de pessoas presas, e mãe de um sentenciado, Maria Railda Silva Alves, o CEPCP não fazia diferença alguma na realidade penitenciária e não melhorava em nada a situação dos presos (Alves, 2013).

O defensor público do estado de São Paulo Patrick Lemos Cacicedo via o CEPCP naquela gestão como demasiadamente controlado pela Secretaria de Administração Penitenciária, o que lhe privava de qualquer poder de transformação da realidade, mesmo assim, valorizou a participação da Defensoria Pública no CEPCP. O Núcleo da Situação Carcerária da Defensoria, sob coordenação de Cacicedo, procurava dialogar com a representante de sua instituição naquele conselho sobre as proposições, casos e debates que lá tramitavam. Enxergava o conselho como um espaço estratégico para atualização de algumas informações sobre as atividades da Secretaria de Administração Penitenciária. Um papel fundamental da representação da Defensoria nesse colegiado era o de resistência contra determinados projetos que prejudicassem os interesses de presos, presas e seus familiares (Cacicedo, 2013). O agente da Pastoral Carcerária de São Paulo, Rodolfo Valente, também não tinha uma boa impressão sobre o Órgão. Contou que a coordenação da 
Pastoral decidira, recentemente, retirar sua representante do CEPCP, pois teriam concluído que perdiam um tempo precioso ali e que não valia gastarem esforços dentro de um órgão sem poder, sem autonomia e submisso aos interesses da Administração Penitenciária. As funções meramente consultivas do órgão seriam instrumentalizadas para a legitimação das políticas penitenciárias do Estado de São Paulo (Valente, 2013).

Denise Blanes, Doutora em Serviço Social e atuante no Instituto Terra, Trabalho e Cidadania, mostrouse um pouco cética em relação às dinâmicas de funcionamento de conselhos de políticas públicas da área de educação que conhecera mais de perto, onde encontrou pessoas despreparadas atuando como conselheiras, levantando a suspeita de que muitos deles atuavam quase que somente visando interesses particulares, individuais ou de suas organizações de origem. A impressão de Blanes especificamente sobre o CEPCP era de que se tratava de um órgão muito burocrático e praticamente sem nenhum poder de decisão. Não se lembrou de alguma conquista atingida diretamente através da atuação desse conselho. Apesar disso, sustentou que é preciso ocupar os espaços políticos que são oferecidos, sobretudo quando se vem de organizações com pouca força política. Estar dentro de um conselho costuma possibilitar o acesso a muitas informações políticas importantes e a contatos que podem ter relevância estratégica (Blanes, 2013).

Uma opinião dissonante, por ser mais entusiasta em relação ao funcionamento do Conselho, apareceu no depoimento da advogada e professora Janaína Conceição Paschoal, conselheira na gestão 2011-2013. Ela garantiu que o ambiente institucional era saudável, reunindo membros de diversas origens e opiniões, em interações ponderadas, onde todos demonstravam boa capacidade de diálogo no debate dos temas mais diversos. Ressaltou ainda a importância da visita a unidades prisionais, mesmo que da forma agendada, o que renderia alguma fiscalização sobre a realidade dos estabelecimentos. Relatou a aproximação do CEPCP da Presidência do Tribunal de Justiça de São Paulo. A partir do estreitamento da relação poderiam ser concretizadas ações institucionais com o condão de influenciar os magistrados no sentido de mitigar a excessiva aplicação de prisões provisórias, fenômeno de sua preocupação (Paschoal, 2013).

Carolina Toledo Diniz, representante da comunidade vinculada ao Instituto de Defesa do Direito de Defesa, conselheira na gestão 2011-2013, também ressaltou a existência de diálogos frutíferos entre os membros durante as reuniões. Ela elogiou a formação eclética dos membros do Conselho, com a possibilidade de troca de conhecimentos de vários campos. Lembrou, por exemplo, de situações em que pessoas com uma visão mais acadêmica mudaram de opinião a partir da argumentação de conselheiros com uma vivência prática maior no contato com a população encarcerada. As pautas sempre chegavam por meio da provocação de algum conselheiro e as reuniões não costumavam ter a presença de alguma pessoa de fora do colegiado. Os "membros da comunidade", como ela, procuravam priorizar as pautas trazidas de redes de organizações civis de defesa de direitos humanos. No intuito de divulgar as atividades e a existência do CEPCP, contou que ela e outros conselheiros desejavam promover uma audiência pública para discutir problemas em torno de um procedimento de apuração de faltas disciplinares, um projeto que acabou não avançando até o final da pesquisa (Diniz, 2013).

No tocante à lógica de representação, tal como nesse último depoimento, foi recorrente nas entrevistas com conselheiros do CEPCP a menção à existência de diálogos no interior de suas entidades e instituições para tratar de pautas discutidas nos colegiados, realizando aqueles processos contínuos de idas e vindas entre representantes e representados, de "autorizações" e "prestações de contas", teorizados por Young (2006) ${ }^{[25]}$. Vale ponderar, entretanto, que a intensidade dessas relações é difícil de ser mensurada apenas por depoimentos. É algo que demandaria uma pesquisa mais detida no cotidiano de cada instituição.

Nota-se que a origem dos membros dos colegiados costuma influenciar bastante a natureza das pautas trazidas para a agenda política de debate. Algumas pautas, porém, são recorrentes e de interesse de atores muito distintos, como a preocupação com a superlotação das unidades prisionais, o que atrai grande interesse das agendas governamentais, de representantes de instituições ligadas ao Judiciário e de militantes de organizações pela defesa de pessoas presas. Assim, por exemplo, problemas envolvendo determinados direitos processuais penais de pessoas presas mais ligados à prática jurídico-penal costumavam ser suscitados 
pelos membros com formação jurídica e militância na defesa processual, caso de alguns dos professores universitários e de membros da assistência judiciária ou da Defensoria Pública ${ }^{[26]}$. Aqueles representantes da comunidade que têm maior contato com a realidade institucional dos presos e de seus familiares costumam trazer para discussão casos mais concretos de violações de direitos humanos.

A conjuntura política do início dos anos 2000 mudou bastante até 2013 em relação ao sistema punitivo em São Paulo. Embora prevalecendo um mesmo partido político no âmbito estadual, mudaram governadores, secretários de Estado e bases parlamentares. Novas organizações da sociedade civil despontaram para conviver com as mais antigas, colaborando para diversificar as pautas trazidas para a esfera pública e os repertórios. O PCC foi ganhando mais força, assumindo crescente destaque no sistema prisional paulista, ganhando visibilidade significativa com as duas megarrebeliões de 2001 e 2006. As disputas sobre a agenda política relacionadas à defesa e promoção de direitos humanos tornaram-se gradativamente mais tensas. Muitos dos problemas no funcionamento do CEPCP refletem conflitos que afloraram ao longo do período no sistema prisional e orbitam frequentemente em torno da temática dos direitos humanos. Reduzido a funções consultivas e sem poder de decisão, frequentemente parecendo subordinado aos interesses das autoridades do Executivo, as impressões dos conselheiros e atores ligados ao sistema prisional acumulam críticas severas ao colegiado, mas também permitem a revelação de pontos positivos do Conselho no tocante à accountability em direitos humanos no sistema penitenciário.

\section{CONSIDERAÇÕES FINAIS}

O CEPCP apareceu como um dos raros espaços institucionais estatais concebidos para garantir assentos para alguns daqueles atores interessados no combate às violações de direitos humanos no sistema prisional, convivendo com governos mais ou menos avessos aos direitos humanos de pessoas presas e com o gradativo fortalecimento de certos atores do lado do "mundo do crime". Seu desenho institucional apresentou alguns limites à representação dessa militância e, ao longo do tempo, o Conselho demonstrou problemas de institucionalização, um funcionamento precário, a descontinuidade de trabalhos, carência em transparência e em prestação de contas, apresentando exíguas contribuições relativas ao cumprimento de suas atribuições institucionais consultivas em relação a políticas criminais e penitenciárias e de "zelar pelo respeito aos direitos e garantias individuais do preso".

O Poder Executivo do estado de São Paulo tem significativa responsabilidade em relação a isso, tanto no que se refere à concepção e ao suporte ao Órgão, quanto no tocante a um histórico de uso instrumental do colegiado de acordo com os interesses da gestão. A falta de poder e de autonomia do Conselho em relação às instituições a serem fiscalizadas são pontos que dificultam ou inviabilizam qualquer tentativa de resistência e mudança.

Porém, mesmo funcionando aquém do desejado, atendendo principalmente a questões pontuais e atingindo uma escala diminuta da população prisional, a existência do Conselho e suas contribuições podem ser também avaliadas em um contexto de soma de esforços em uma rede maior de accountability. Nesse sentido, os fluxos de informação entre agentes do Estado e a sociedade civil perfazem a principal virtude desse Conselho em relação à temática de direitos humanos ${ }^{[27]}$. Se há uma tendência das agências do Estado, em geral, a um processo de insulamento ${ }^{[28]}$, é de se intuir que o recurso da informação ganha uma relevância capital no subsídio a estratégias e ações dos atores no campo penal.

$\mathrm{O}$ assento nesse colegiado e a vivência como conselheiro nas reuniões, em eventos e em visitas a unidades prisionais permitem aos atores individuais e às entidades e instituições que representam algum aprendizado nos processos deliberativos, a tomada de consciência sobre questões pertinentes à agenda política da gestão penitenciária e sobre denúncias de violações de direitos, quando não ocorre a sua constatação in loco. Esse contato entre autoridades e representantes da sociedade civil organizada pode estimular e até apressar 
determinados movimentos institucionais, no sentido de prevenção de infrações, reparação de danos e punição dos responsáveis.

\section{BiBLIOGRAFIA}

ADORNO, Sérgio (1999). "Insegurança versus direitos humanos: entre a lei e a ordem". Tempo social - Revista de Sociologia da Universidade de São Paulo, vol. 11, n. 2, pp. 129-153. Recuperado de http://www.nevusp.org/ portugues $/$ index.php?option $=$ com_content\&task $=$ view\&id $=1063$.

ALMEIDA, Carla. TATAGIBA, Luciana (2002). "Os conselhos gestores sob o crivo da política: balanços e perspectivas". Serviço Social \& Sociedade, n. 109. São Paulo: Cortez, pp. 68-92. Recuperado de http:// www.scielo.br/scielo.php?script $=$ sci_arttext\&pid $=$ S0101-66282012000100005.

ALVES, Maria Railda Silva (2013). Maria Railda Silva Alves: depoimento [abr. 2013]. Entrevistador: Otávio Dias de Souza Ferreira. São Paulo: UNIFESP, 2013. Depoimento cedido para pesquisa de mestrado do entrevistador.

ANTONIO, Arlete da Silva (2013). Arlete da Silva Antônio: depoimento [ago. 2013] Entrevistador: Otávio Dias de Souza Ferreira. São Paulo: UNIFESP, 2013. Depoimento cedido para pesquisa de mestrado do entrevistador.

FERREIRA, Otávio Dias de Souza Ferreira (2014). Agências de administração penitenciária de São Paulo com potencial de accountability em direitos humanos no pós redemocratização. Dissertação de Mestrado. Departamento de Ciências Sociais. Universidade Federal de São Paulo. Guarulhos: Unifesp. Recuperado de http://www2.unifesp.br/ciencias_sociais/dissertacoes-defendidas-versao-final/otavio-dias-de-souza-ferreira.

BARATTA, Alessandro (2006). Criminologia y sistema penal - compilación in memoriam. Buenos Aires: Editorial IBdeF.

BIONDI, Karina (2010). Junto e misturado: uma etnografia do PCC. São Paulo: editora Terceiro Nome.

BLANES, Denise (2013). Denise Blanes: depoimento [abr. 2013]. Entrevistador: Otávio Dias de Souza Ferreira. São Paulo: UNIFESP, 2013. Depoimento cedido para pesquisa de mestrado do entrevistador.

BRASIL (1980a). Portaria n. 658, de 24 de junho de 1980. Dispõe sobre a Criação do Conselho Nacional de Política Penitenciária.

BRASIL (1980b). Decreto n. 85.345, de 11 de novembro de 1980. Regulação do Conselho Nacional de Política Penitenciária. Recuperado de http://www2.camara.leg.br/legin/fed/decret/1980-1987/decreto-85345-11novembro-1980-434901-norma-pe.html.

BRASIL (1984a). Lei n. 7.209, de 11 de julho de 1984. Parte Geral do Código Penal . Recuperado de http:// www.planalto.gov.br/ccivil_03/leis/1980-1988/17209.htm.

BRASIL (1984b). Lei n. 7.210, de 11 de julho de 1984. Lei de Execução Penal . Recuperado de http:// www.planalto.gov.br/ccivil_03/leis/17210.htm.

BRASIL (1987). Resolução n. 22, de 31 de março de 1987. Resolução do Conselho Nacional de Política Criminal e Penitenciária. Recuperado de http://www.justica.gov.br/seus-direitos/politica-penal/cnpcp-1/resolucoes/ resolucoes-arquivos-pdf-de-1980-a-2015/resolucao-ndeg-22-de-31-de-marco-de-1987.pdf.

BRASIL (2011). Lei n. 12.527, de 18 de novembro de 2011. Lei de Acesso à Informação. Recuperado de http:// www.planalto.gov.br/ccivil_03/_ato2011-2014/2011/lei/l12527.htm.

BRASIL (2014). Ministério da Justiça. Departamento Penitenciário Nacional. Plano Diretor do Sistema Penitenciário: Diagnóstico, ações e resultados. Brasília: Depen/MJ. Recuperado de http://portal.mj.gov.br/main.asp?View $=\{$ E7CD13B5-D38A-44D1-8020EB9BF0F41E93\}\&BrowserType=IE\&LangID =pt-br ms=itemID\%3D\%7BF329E71B-B4C8-40E2BF58-6F2065E5614D\%7D\%3B\&UIPartUID=\%7B2868BA3C-1C72-4347-BE11-A26F70F4CB26\%7D.

CACICEDO, Patrick (2013). Patrick Cacicedo: depoimento [mai. 2013] Entrevistador: Otávio Dias de Souza Ferreira. São Paulo: UNIFESP, 2013. Depoimento cedido para pesquisa de mestrado do entrevistador.

CALDEIRA, Teresa Pires do Rio (1991). "Direitos humanos ou 'privilégios de bandidos'? Desventuras da democratização brasileira”. Novos Estudos - Cebrap, N. 30, pp. 162-174. 
CARDIA, Nancy. Direitos humanos: ausência de cidadania e exclusão moral. São Paulo: Comissão de Justiça e Paz, 1995.

CHRISTIANO, Thomas (2007). “A importância da deliberação pública”. In: WERLE, Denison. MELO, Rúrion S. (org.). Democracia deliberativa. São Paulo: Editora Singular, Esfera Pública, pp. 81-114.

CUNHA, Eleonora S. M. ALMEIDA, Débora C. R. de. FARIA, Cláudia F. RIBEIRO, Uriella C. (2011). “Uma estratégia multidimensional de avaliação dos conselhos de políticas: dinâmica deliberativa, desenho institucional e fatores exógenos". In PIRES, Roberto R. C.(org.). Efetividade das instituições participativas no Brasil: estratégias de avaliação. Brasília: Ipea.

DAGNINO, Evelina (2002). "Sociedade civil, espaços públicos e a construção democrática no Brasil: limites e possibilidades”. In: DAGNINO, Evelina (org.), Sociedade Civil e espaços públicos no Brasil. São Paulo: Paz e Terra.

DIAS, Camila Caldeira Nunes (2013). PCC: hegemonia nas prisões e monopólio da violência. São Paulo: Saraiva.

DIAS, José Carlos. José Carlos Dias: depoimento [mar. 2014]. Entrevistador: Otávio Dias de Souza Ferreira. São Paulo: UNIFESP, 2013. Depoimento cedido para pesquisa de mestrado do entrevistador.

DINIZ, Carolina Toledo (2013). Carolina Toledo Diniz: depoimento [jun. 2013]. Entrevistador: Otávio Dias de Souza Ferreira. São Paulo: UNIFESP, 2013. Depoimento cedido para pesquisa de mestrado do entrevistador.

ELSTER, John. "Régimen de mayorias y derechos individuales" (1998). IN Stephen Shute e Susan Hurley (eds), De los derechos humanos. Madri: Editorial Trotta.

EVANS, Peter (2004). Autonomia e parceria: Estados e transformação industrial. Rio de Janeiro: Editora UFRJ.

FARIA, Carlos Aurélio Pimenta de (2005). A política da avaliação de políticas públicas. Revista Brasileira de Ciências Sociais, vol. 20, n. 59, pp. 97-109.

FOUCAULT, Michel (1979). Microfísica do poder. $8^{\mathrm{a}}$ ed. Trad. Roberto Machado. Rio de Janeiro: Graal.

FUNG, A. WRIGHT, E. O (2003). “Thinking about Empowered Participatory Governance”. In: FUNG, A. WRIGHT, E. O. (ed.), Deepening democracy: institutional innovation in Empowered Participatory Governance. London: Verso.

GOES, Eda Maria (2009). A recusa das grades: rebeliões nos presídios paulistas: 1982-1986. São Paulo: Ibccrim.

GOHN, Maria da Glória (2006). "Conselhos gestores e gestão pública”. Ciências Sociais Unisinos, v. 42, n. 1, pp. 5-11, jan./abr. Recuperado de http://revistas.unisinos.br/index.php/ciencias_sociais/article/view/6008.

GOIFMAN, Kiko, Kiko Goifman: depoimento [ago. 2013]. Entrevistador: Otávio Dias de Souza Ferreira. São Paulo: UNIFESP, 2013. Depoimento cedido para pesquisa de mestrado do entrevistador.

GOODING, Robert E. DRYZEK, John S (2008). Making use of minipublics. IN Robert E. Gooding, Innovating democracy: Democratic Theory and practice after the deliberative turn. Nova Iorque: Oxford University Press.

GURZA LAVALLE, Adrian, ISUNZA, Ernesto (2011). “A trama da crítica democrática: da participação à representação e à accountability”. Lua Nova - Revista de Cultura e Política, v.84, p.95-140. Recuperado de http://www.scielo.br/pdf/ln/n84/a05n84.pdf.

GURZA LAVALLE, Adrian. HOUTZAGER, Peter P. CASTELLO, Graziela (2012). "A construção política das sociedades civil”. In: GURZA LAVALLE, Adrian (org). Horizonte da política: questões emergentes e agendas de pesquisa. São Paulo: Ed. Unesp: Cebrap: CEM.

GURZA LAVALLE, Adrian. ISUNZA, Ernesto (2012). “Arquitetura da participação e controles democráticos no Brasil e no México”. Novos estudos - Cebrap, n.92, pp. 105-121. Recuperado de http://dx.doi.org/10.1590/ S0101-33002012000100007.

HOLSTON, James (2008). Dangerous spaces of citizenship: gang talk, rights talk and rule of law in Brazill. In: Insurgent Citizenship: disjunctions of democracy and modernity in Brazil. Princeton: University Press.

ISUNZA VERA, Ernesto. GURZA LAVALLE, Adrian (2014). Desvelando cauces recurrentes. Los controles democráticos no electorales como prácticas de resignificación en la construccíón democrática. IN Ernesto Isunza Vera (org), Controles democráticos no electorales y régimen de rendición de cuentas. En busqueda de respostas comparativas: México, Colombia, Brasil, China y Sudafrica. México: Ciesas. 
LIPSKY, Michael (2010). Street-level bureaucracy: dilemas of the individual in public services. 30th aniversary expanded edition. Nova Yorque: Russel Sage Foundation.

LOPES JR. Aury (2007). Direito processual e sua conformidade Constitucional - vol. 01. Rio de Janeiro: Lumen Juris Editora.

MALVEZZI, Paulo César (2013). Paulo César Malvezzi: depoimento [dez. 2013]. Entrevistador: Otávio Dias de Souza Ferreira. São Paulo: UNIFESP, 2013. Depoimento cedido para pesquisa de mestrado do entrevistador.

MARQUES, Adalton (2010). “'Liderança', 'proceder' e 'igualdade': uma etnografia das relações políticas no Primeiro Comando da Capital”. Etnográfica, n. 14 (2), p. 311-335. Recuperado de http://www.scielo.gpeari.mctes.pt/ scielo.php?pid=S0873-65612010000200005\&script=sci_arttext.

MARQUES, Eduardo (2013). As políticas públicas na Ciência Política. In: Marques, Eduardo e Faria, Carlos Aurélio Pimenta de (org.). “A política pública como campo multidisciplinar”. São Paulo: Unesp/Ed. Fiocruz.

MIGUEL, Luis Felipe (2011). "Representação democrática: autonomia e interesse ou identidade e advocacy". Lua Nova - Revista de Cultura e Política, no 84, pp. 25-63. Recuperado de http://www.scielo.br/pdf/ln/n84/ a03n84.pdf.

PATEMAN, Carole (1992). Participação e teoria democrática. Tradução Luiz Paulo Rouanet. Rio de Janeiro: Paz e Terra.

PASCHOAL, Janaína Conceição (2013). Janaína Conceição Paschoal: depoimento [mai. 2013]. Entrevistador: Otávio Dias de Souza Ferreira. São Paulo: UNIFESP, 2013. Depoimento cedido para pesquisa de mestrado do entrevistador.

SAMPAIO, Paulo César (2013). Paulo César Sampaio: depoimento [jul. 2013]. Entrevistador: Otávio Dias de Souza Ferreira. São Paulo: UNIFESP, 2013. Depoimento cedido para pesquisa de mestrado do entrevistador.

SÃO PAULO [Estado] (1987a). Decreto Estadual n. 26.981, de 13 de maio de 1987. "Decreto de instituição do Conselho Estadual de Política Criminal e Penitenciária”. Recuperado de https://www.al.sp.gov.br/ norma/ 48578 .

SÃO PAULO [Estado] (1987b). Resolução n. 37, de 19 de agosto de 1987. "Regimento Interno do Conselho Estadual de Política Criminal e Penitenciária”.

SÃO PAULO [Estado] (1991). Lei Estadual n. 7.634, de 10 de dezembro de 1991. "Lei sobre a composição e a competência do Conselho Estadual de Política Criminal e Penitenciária”. Recuperado de https://governosp.jusbrasil.com.br/legislacao/181180/lei-7634-91.

SÃO PAULO [Estado] (2013). Secretaria de Administração Penitenciária. Conselho Estadual de Política Criminal e Penitenciária. São Paulo. Recuperado de http://perfil.sp.gov.br/site/exibe.asp?entidadecodigoid=669\&tt=CONSELHO\%20ESTADUAL\%20DE \%20POL\%C3\%8DTICA\%20CRIMINAL\%20E\%20PENITENCI\%C3\%81RIA.

SMITH, Graham (2009). Democratic Innovation: designing institutions for citizen participation. Nova Iorque: Cambridge University Press.

TATAGIBA, Luciana (2002). “Os conselhos gestores e a democratização de políticas públicas no Brasil”. In: DAGNINO, Evelina (org.), Sociedade civil e espaços públicos no Brasil. São Paulo: Paz e Terra.

TEIXEIRA, Alessandra (2009). Prisões de exceção: política penal e penitenciária no Brasil Contemporâneo. Curitiba: Juruá editora.

VALENTE, Rodolfo (2013). Rodolfo Valente: depoimento [abr. 2013]. Entrevistador: Otávio Dias de Souza Ferreira. São Paulo: UNIFESP, 2013. Depoimento cedido para pesquisa de mestrado do entrevistador.

WARREN, Mark E (2006). "What can democratic participation mean today". Political Theory, vol. 30, n. 5, pp. 677-701. Recuperado de http://www.jstor.org/stable/3072498?seq=1\#page_scan_tab_contents.

YOUNG, Iris Marion (2006). "Representação política, identidades e minorias". Lua Nova - Revista de Cultura e Política, $n^{\circ}$ 67. Recuperado de http://www.scielo.br/pdf/ln/n67/a06n67.pdf/.

ZAFFARONI, Eugenio Raúl. BATISTA, Nilo. ALAGIA, Alejandro. SLOKAR, Alejandro (2003). Direito Penal Brasileiro: primeiro volume. $2^{\mathrm{a}} \mathrm{ed}$. Rio de Janeiro: Revan. 


\section{Notas}

[1] Os "conselhos gestores de políticas públicas" previstos na Constituição Federal estão inseridos em políticas de educação, assistência social e saúde. Além de competências consultivas, possuem poderes de sanção e maior autonomia. Para saber mais sobre esse debate, recomenda-se a leitura de Gohn (2006).

[2] Estão previstos na Lei de Execução Penal (Brasil, 1984b), nas Regras Mínimas das Nações Unidas para Tratamento do Recluso, na Constituição Federal de 1988 e na normativa penal e processual penal brasileira.

[3] Durante praticamente todo o período de pesquisa de campo sobre o colegiado, em 2013, ele se manteve inativo, sem reuniões e atividades, em um inusitado intervalo entre o final de uma gestão e a nomeação da seguinte.

[4] Em resposta positiva ao tal requerimento, a Secretaria de Administração Penitenciária do estado de São Paulo (SAP/SP) disponibilizou o acesso a quatro processos contendo documentos referentes ao Conselho, em sua maioria ofícios e decisões do Secretário de Estado e do Governador para nomear os integrantes do Conselho em várias gestões desde sua criação. Não havia, entretanto, sequer uma ata de reuniões. Os números identificadores dos processos aparecem no final das referências bibliográficas.

[5] Considerando a natureza da temática e os eventuais constrangimentos que ela possa provocar aos depoentes, avaliou-se que o mais adequado seria a não gravação das entrevistas, elegendo-se a riqueza de um depoimento espontâneo como um ganho mais relevante, ainda que em detrimento de uma possível perda de aspectos gestuais do informante e do risco de alguma imprecisão na transcrição de algumas declarações. Os questionários foram semiabertos, baseados em certas temáticas consideradas irrenunciáveis sobre a autonomia e o funcionamento do Conselho, a lógica de representação e dos processos deliberativos e suas relações institucionais, questões de pauta e agenda e as contribuições do colegiado no tocante aos direitos humanos no sistema prisional.

[6] Sobre as políticas adotadas naquele período, recomenda-se a leitura da pesquisa de Goes (2009).

[7] Conforme mencionado, essa lei foi concebida em um período curto da história de São Paulo em que a administração do sistema penitenciário ficou sob a alçada da Secretaria de Segurança Pública, entre março de 1991 e novembro de 1992. Antes desse período ficava sob a responsabilidade da Secretaria de Justiça, e depois, da Secretaria de Administração Penitenciária. Apesar das mudanças legais, até hoje a lei de fundação do CEPCP não foi atualizada e alguns de seus dispositivos dependem de interpretações para terem aplicação prática.

[8] Foram quatro novas nomeações na gestão 2004-2006, sete na gestão 2008-2010, e cinco na gestão 2011-2013.

[9] A afirmação é facilmente constatada na observação das datas de publicação no Diário Oficial do Estado (DOE) do ato do Governador do Estado de São Paulo que designa a composição do conselho para cada uma das gestões. A partir do ato, pode-se contar o prazo de um ano de duração da gestão. Embora outra interpretação possa preconizar, como termo inicial do mandato o momento da posse dos conselheiros, o regimento interno do CEPCP - Resolução no 37/1987, da Secretaria de Estado dos Negócios da Justiça -, em seu artigo segundo, dispõe que o mandato é “contado a partir da data da designação".

[10] Na maioria das gestões analisadas, conforme a previsão legal, a Secretaria da Justiça indicou os dois professores. Entretanto, na gestão 2011-2013 e na gestão que estava em estágio de constituição quando da conclusão da pesquisa, a indicação coube ao reitor da Universidade de São Paulo. No caso dos representantes da comunidade, houve gestão em que o Conselho de Defesa da Pessoa Humana (Condepe) fez as indicações, outra em que o próprio Secretário de Administração Penitenciária tomou para si a função e outra gestão em que determinadas organizações civis foram diretamente consultadas em detrimento de outras.

[11] Trata-se do artigo $4^{\circ}$ da Lei Estadual n. 7.634, de 10 de dezembro de 1991 (São Paulo, 1991).

[12] Abrange experiências de iniciativa estatal de regulação de regras de participação em órgãos que reúnem atores estatais - do Governo e de outras instituições públicas - e sociais (Isunza Vera \& Gurza Lavalle, 2014).

[13] Não devem ser confundidos, entretanto, com aqueles conselhos de políticas públicas previstos na Constituição Federal de 1988, tornados obrigatórios em vários níveis da organização federativa, frutos da pressão de movimentos sociais e com poderes deliberativos e executivos sobre a formulação e o controle de políticas públicas setoriais tais como aqueles da área de saúde, assistência social e infância e adolescência (Tatagiba, 2002).

[14] A “partilha de poder” existente no âmbito de conselhos de políticas públicas previstos na constituição deve-se à previsão de mecanismos especiais como o chamado poder de "sanção" e mecanismos de natureza executiva (Dagnino, 2002).

[15] Para saber mais sobre esse debate, vale ler o balanço de literatura elaborado por Marques (2013) e por Faria (2005). 
[16] Lipsky (2010) cunhou a expressão street-level bureaucracy ou por uma livre tradução: "burocracia do nível de rua". Trata basicamente da valorização do papel das burocracias mais baixas das instituições estatais em um processo de implementação de políticas públicas.

[17] Warren (2003) afirma: "participation is democratic when every individual potentially affected by a decision has an equal opportunity to affect the decision". Smith (2009, p. 01) define as "democratic innovations" como "institutions that have been specifically designed to increase and deepen citizen participation in the political decision-making process".

[18] Nessa esteira, Thomas Christiano sustenta que uma das principais preocupações de uma discussão pública deve ser a garantia de que todos os indivíduos tenham o acesso igual às "condições cognitivas para a tomada de decisões". O autor define "condições cognitivas" como aquelas condições "que habilitam a pessoa a entender melhor o que está em jogo numa decisão, bem como a melhor discernir a decisão correta” (Christiano, 2007).

[19] Caldeira (1991), Cardia (1995) e Holston (2008) revelam aspectos da dimensão de impopularidade dos direitos de pessoas presas em São Paulo, mostrando processos relacionados a campanhas públicas contra tais direitos desde o início da redemocratização.

[20] Como sugere Foucault (1979), trata-se de fenômeno que não é novo e nem exclusivo do Brasil.

[21] Sobre a natureza de interesses contramajoritários e o risco de tirania da maioria, recomenda-se a leitura de contribuições de Elster (1998).

[22] Ver a lista de pessoas consultadas sobre o conhecimento acerca da existência do CEPCP ao final das referências bibliográficas.

[23] Recordou-se, por exemplo, da presença de Josephina Baçarica, ex-presidenta da Comissão de Justiça e Paz, e de Michael Mary Nolam, da Pastoral Carcerária, que costumavam trazer problemas emergenciais ligados a prisões femininas (Goifman, 2013).

[24] A advogada reclamou, por exemplo, que ela e mais dois colegas pretendiam visitar presídios problemáticos, mas que só conseguiram ir a uma unidade feminina, escolhida unilateralmente pela presidenta, onde a Funap havia desenvolvido algum projeto (Antonio. 2013).

[25] Nesse sentido, nas entrevistas de Cacicedo (2013), Blanes (2013) e Valente (2013), os depoentes narraram situações em que foram debatidos em suas organizações assuntos trazidos a partir da participação no órgão representativo.

[26] Isso apareceu nas declarações de Paschoal (2013) e Cacicedo (2013).

[27] Vale mencionar que essa qualidade aparece no quadro de tipos de lógica de ação da arquitetura de participação como sistema de controles democráticos, teorizada por Gurza Lavalle \& Isunza (2012).

[28] É uma das premissas básicas dos estudos da literatura chamada de neoinstitucionalismo histórico. Para mais informações, ver Evans (2004).

\section{BY-NC-ND}

